\title{
AUMENTANDO A PRODUTIVIDADE - A LUBRIFICAÇÃO CONTRIBUINDO PARA ALCANÇAR O MÁXIMO DE EFICIÊNCIA NA PRODUÇÃO DE AÇO*
}

Marcelo Cervantes Del Rio Baptista ${ }^{1}$ Miguel Preciado Pérez ${ }^{2}$ Otávio Henrique de Souza ${ }^{3}$ José Elias Fiorotto 4

\section{Resumo}

Nos últimos anos a indústria siderúrgica no Brasil vem sofrendo um processo lento e cruel de encolhimento de sua participação no PIB, em decorrência de diversos fatores políticos e econômicos. Apesar do grande esforço por parte das empresas, a capacidade de produção de aço pouco cresceu neste período, permitindo que as despesas cresçam mais rápido do que as receitas. Esses fatores têm mostrado aos profissionais do setor que a mudança do cenário só ocorrerá ao se produzir com o máximo de eficiência. O objetivo deste trabalho é demonstrar que a lubrificação tem grande participação no aumento da produtividade e redução de custos da manutenção. Em suma, será apresentado um estudo sobre como a lubrificação correta influencia no aumento da produtividade das siderúrgicas. Com base nos resultados dos testes realizados em duas grandes empresas do setor, este trabalho demonstra o aumento significativo de performance no Mandril da bobinadeira e mancais dos convertedores, após estudo detalhado da lubrificação.

Palavras-chave: Lubrificação adequada; Graxa; Aumento de eficiência.

\section{IMPROVING PRODUCTIVITY - LUBRICATION CONTRIBUTES TO REACH THE MAXIMUM EFFICIENCY IN STEEL PRODUCTION}

\begin{abstract}
In recent years, the steel industry in Brazil has been suffering a slow and cruel process of shrinking of its share in the GDP, due to various political and economic factors. Despite the great efforts by companies, the steel production capacity increased slightly in this period, allowing expenses to grow faster than revenues. These reasons have shown to industry professionals that the change of this scenery will take place if they produce at maximum efficiency. The present study is aimed at demonstrating that lubrication has contributed a lot to increase the productivity and to reduce the maintenance costs. In short, this study shows how the proper lubrication affects the productivity increase of steel industries. Based on test results carried out by two big companies in the sector, this study shows a significant increase in performance in the Down Coiler's mandreel and Converter bearings after improvements in lubrication.
\end{abstract}

Keywords: Proper lubrication; Grease; Increased efficiency.

1 Eng. de Produção, Responsável Técnico Siderúrgicas, Assessor Técnico, Departamento de Engenharia de Aplicação, Interlub Group, São Bernardo do Campo, São Paulo, Brasil.

2 Eng. Químico, Especialista em lubrificantes de alta performance, Gerente de Tecnologia, Departamento de Desenvolvimento, Interlub Group, Guadalajara, Jalisco, México.

3 Eng. Mecânico, Especialista em Laminação, Engenheiro, Laminação de Tiras a Quente, Companhia Siderúrgica Nacional, Volta Redonda, Rio de Janeiro, Brasil.

4 Mercadólogo, Especialista no mercado siderúrgico de lubrificantes, Consultor Técnico, Desenvolvimento de Negócios, Interlub Group, São Bernardo do Campo, São Paulo Brasil. 


\section{INTRODUÇÃO}

O Brasil ocupa a $9^{\circ}$ posição no ranking dos principais países produtores de aço no mundo. Com capacidade instalada de 48 milhões de toneladas por ano, em 2015 foram produzidas cerca de 32,5 milhões de toneladas. Uma ligeira queda em relação à produção registrada em 2014 , de 33,9 milhões de toneladas.

Em um período de 14 anos, o Brasil aumentou sua produção de aço em $21 \%$, comparando o total produzido entre os anos 2000 e 2014.

Segundo a World Steel Association [1], a China, que é o maior produtor de aço do mundo, cresceu aproximadamente $800 \%$ no mesmo período.

Não somente o setor siderúrgico obteve pouco crescimento, de uma maneira geral toda a indústria nacional cresceu pouco ou retraiu, perdendo competitividade, aumentando custos e diminuindo sua participação no Produto Interno Bruto.

Corroborando com este cenário, a produtividade brasileira possui o pior indicador entre 11 países, segundo estudo da Confederação Nacional da Indústrias - CNI sobre este tema [2].

A figura 1 mostra a produtividade, considerando produto por hora trabalhada.

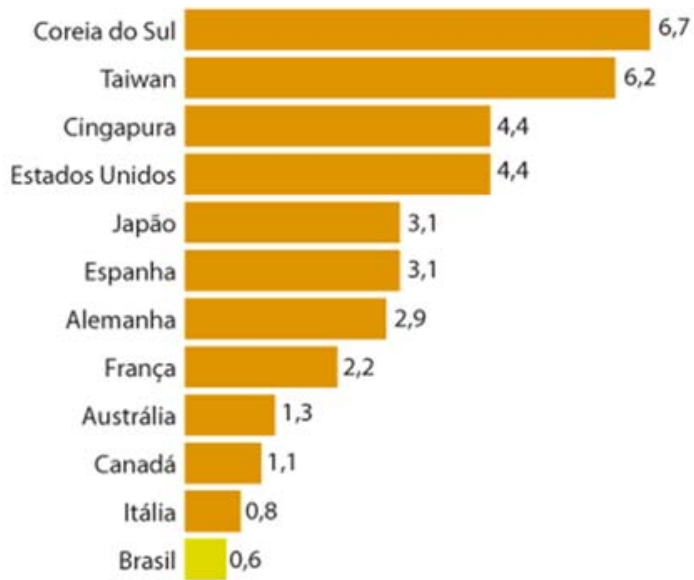

Figura 1. Produtividade entre a década 2002 a 2012 - Produto por hora trabalhada.

Segundo a McKinsey Global Institute [3], um terço da diferença entre a produtividade do Brasil e a dos Estados Unidos está associada a dois fatores: ao fato da modesta renda per capita da população incentivar a busca por produtos e serviços cada vez mais baratos e a questão relativa ao baixo custo da mão de obra comparado ao custo do capital. Isso desestimula certos investimentos que poderiam aumentar a produtividade.

Sobre os custos na indústria, produzir no Brasil ficou mais caro no ano de 2015.

A CNI [4] aponta elevação de $8,1 \%$ no indicador de custos industriais (ICI) entre 2014 e 2015.

O indicador é formado a partir das variáveis - energia elétrica, custo do capital de giro, custo da produção, custo com mão de obra, custos com bens intermediários e custo tributário - Todos esses itens sofreram elevação, exceto custos tributários.

A figura 2 ilustra o aumento do custo de cada variável que compõe o indicador de custos industriais. 


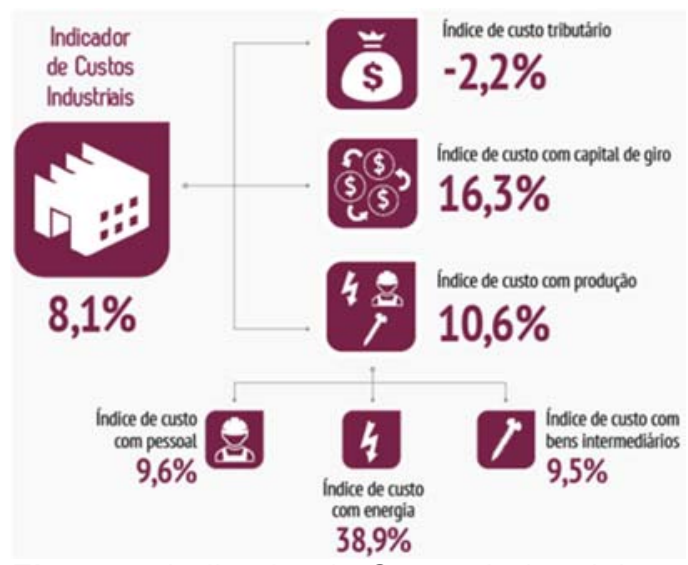

Figura 2. Indicador de Custos Industriais.

De fato, a análise macro deste contexto, abordando fatores econômicos, políticos e estruturais, revela sua parcela de influência na produtividade das empresas. Porém, a análise detalhada da produtividade, aquela feita no chão de fábrica, especificamente nos bens de capital, mostra inúmeras oportunidades de melhoria da eficiência da produção no curto prazo e de baixo custo.

O objetivo deste trabalho, é demonstrar que a lubrificação adequada, realizada em rolamentos, buchas, pinos, guias ou planos inclinados, tem grande participação no aumento da produtividade. Para isso, serão analisados dois estudos de casos em duas siderúrgicas onde houve melhorias significativas no desempenho do equipamento e processo.

\subsection{Revisão Bibliográfica}

Segundo Robertson [5], a principal função da lubrificação é interpor, entre duas partes em contato e com movimento relativo, uma substância de baixa tensão de cisalhamento capaz de diminuir a fricção e o desgaste.

Para Gomes e colegas [6], a lubrificação é a forma mais antiga de manutenção preventiva. Ao ser realizada adequadamente, se alcança, aumento de produtividade e redução de custos.

Já Cash [7] assume que a lubrificação é muito mais do que apenas reduzir atrito e desgaste, há outras funções também benéficas e que influenciam no desempenho do elemento lubrificado. Uma delas é a proteção contra a corrosão pelo filme que protege a superfície lubrificada contra água ou outros fluidos. Não obstante, o lubrificante funciona como agente inibidor de contaminação, por ser o meio de transporte de partículas contaminadas até o filtro. O lubrificante ainda pode auxiliar no controle de temperatura, sendo responsável pela transferência de calor de um ponto quente até um ponto onde a energia térmica possa ser dissipada.

Seguindo por essa linha de raciocínio, Carreteiro e Moura [8] afirmam que a lubrificação somente ocorre com a redução do atrito entre duas superfícies em contato e com movimento relativo, por meio da aplicação de uma substância entre elas, desde que a espessura dessa substância entre as superfícies seja maior que a soma das alturas das rugosidades de cada uma delas.

Gunther [9] comenta que qualquer material que reduza o atrito pode ser entendido como lubrificante, seja ele sólido, líquido, ou gasoso. Além disso, ele convida a refletir sobre a lubrificação mais adequada. Segundo o autor, para uma boa 
lubrificação deve-se observar quais são as propriedades do lubrificante requeridas para o ponto de aplicação.

Sabe-se então que para uma lubrificação adequada se faz necessário o máximo de cuidados acerca da escolha do lubrificante, meios de aplicação, quantidades e período entre aplicações.

Na teoria isso já é conhecido, entretanto não se observa cuidados neste âmbito em muitos setores da indústria. Ainda que tenha havido grandes melhorias no campo do conhecimento e aplicação sobre a abrangência da lubrificação, há empresas que negligenciam esta tarefa. Como resultado, falhas prematuras dos componentes ocorrem com mais frequência, ocasionando paradas não programadas.

A lubrificação é acompanhada à risca pelos fabricantes de rolamentos. Todos os fabricantes apontam o lubrificante como responsável pelo bom funcionamento deste componente.

Segundo a Schaeffler [10], a porcentagem das falhas prematuras de um rolamento diretamente atribuídas ao lubrificante corresponde a 55\%.

A figura 3 apresenta o gráfico das causas das falhas prematuras.

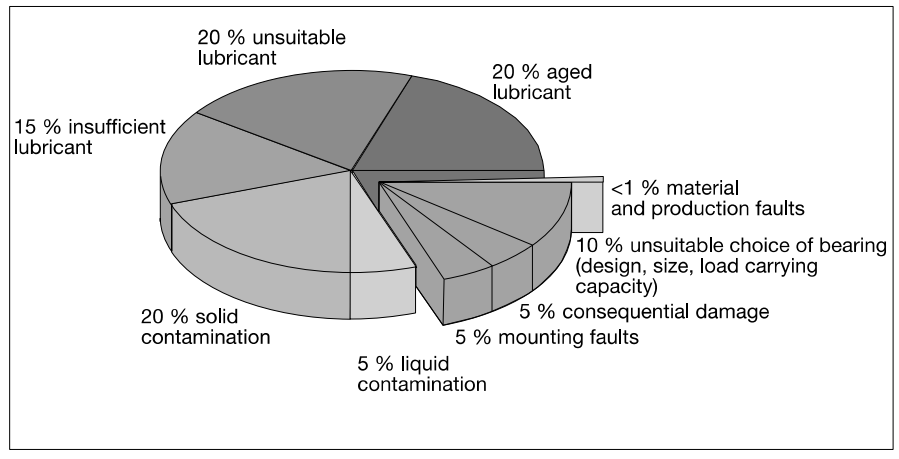

Figura 3. Causas das falhas prematuras dos rolamentos.

\subsection{Composição de um lubrificante - Graxa.}

Uma graxa é composta por basicamente três elementos. Espessante, óleo base e aditivos. A figura 4 mostra a proporção de cada elemento em uma graxa.

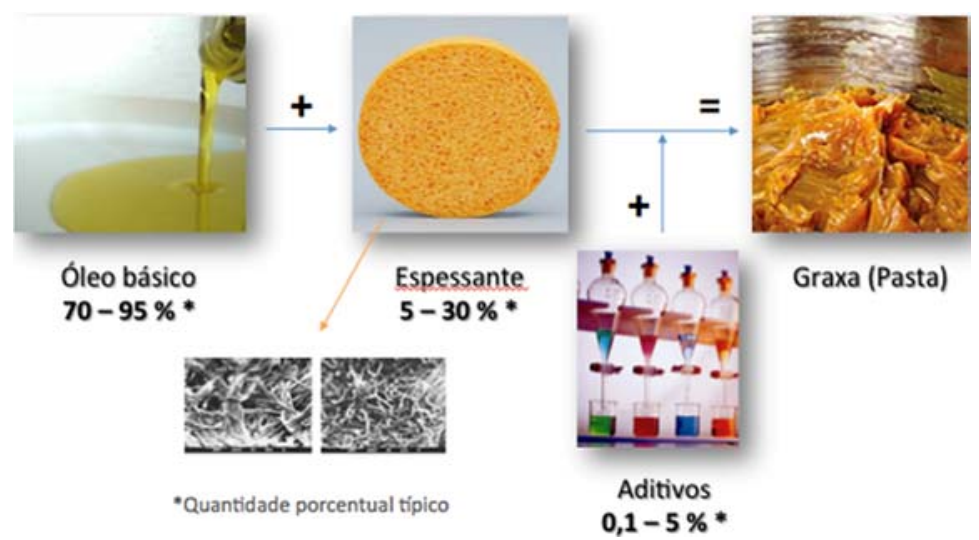

Figura 4: Composição das graxas.

Para Klamann [12], graxa é definida como um produto sólido ou semilíquido que representa a dispersão de um espessante em um líquido lubrificante e que deve preencher às seguintes exigências: 
- Com lenta separação de óleo, a graxa deve liberar quantidade suficiente do líquido lubrificante para reduzir o atrito e desgaste nos rolamentos sob grande variação de temperatura e longos períodos de tempo.

- Na lubrificação de rolamentos, devem ser mecanicamente estáveis e atuar como barreira contra água ou substâncias abrasivas.

- Manter-se consistente mesmo quando o rolamento sofrer leve estresse mecânico.

- Deve proteger contra a corrosão e possuir satisfatória adesividade.

- Deve resistir à pequenas quantidades de sujeira sem perder sua funcionalidade.

- Efeito contrário aos fluidos newtonianos, sua viscosidade depende da taxa de cisalhamento, tempo de corte e pré tratamento.

As graxas mais encontradas no mercado atual podem ser de base poliuréia, lítio, cálcio, bário, bentonas, asfálticas, fluoradas e seus complexos de cada base.

No setor siderúrgico, historicamente foram usadas graxas de base bentonita, complexo de alumínio e lítio para a lubrificação dos rolamentos das cadeiras de laminação. Lubrificantes que são produzidos em larga escala, têm um baixo custo relativo e portanto são usados com muita frequência em diversos equipamentos da planta.

Graxas obtidas com essas bases funcionam bem como elemento inibidor de atrito, entretanto falham em outras propriedades de grande relevância na confiabilidade do equipamento, como por exemplo, propriedades de vedação, baixa resistência a água, adesividade para suportar velocidades variáveis e resistência à alta temperatura. Assim sendo, faz-se necessário a adoção de períodos curtos de relubrificação para manter as máquinas funcionando, aumentando muito o consumo de lubrificante e custos com mão de obra.

Segundo a FAG [13], para determinar uma graxa adequada é importante conhecer todas as características da máquina e do rolamento em questão. Suas condições de operação, método de aplicação e manutenção para atingir o máximo desempenho.

\subsection{Processo de fabricação de graxas especiais}

A obtenção de graxa se dá através de uma série de reações químicas entre as matérias primas dentro de um reator de grandes proporções na qual se controla, automaticamente variáveis como temperatura, pressão, tempo e agitação no tanque. Cada graxa requer uma determinada sequência de combinações entre estas variáveis para que o produto final tenha as propriedades determinadas no projeto. A figura 5 ilustra os elementos necessários para a produção de graxas especiais. 


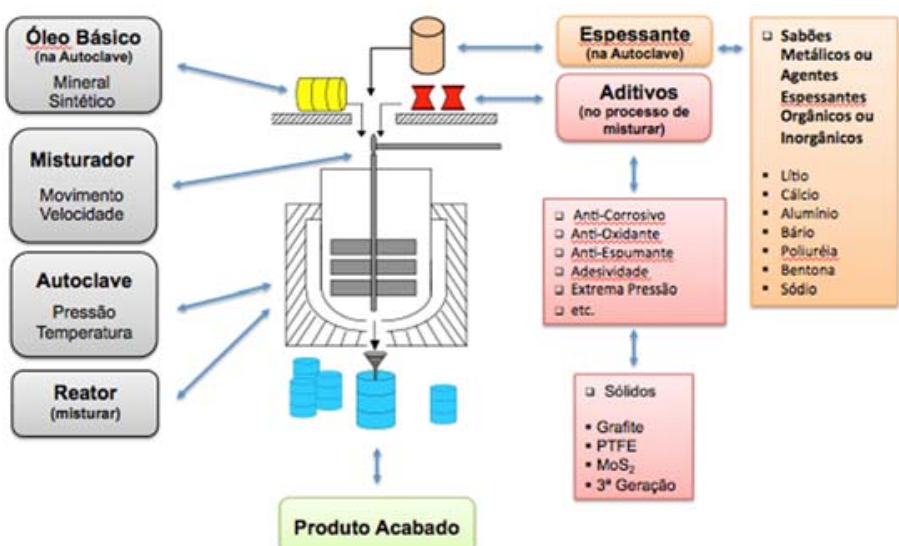

Figura 5: Matérias primas e equipamentos básicos para fabricação de graxas especiais.

Após a saída do reator, a graxa passa por mais um equipamento chamado moinho até que finalmente possa ser envasada e destinada para a distribuição. Neste equipamento a graxa será laminada com o objetivo de homogeneizar sua consistência e estrutura.

\section{MATERIAIS E MÉTODOS}

Para a preparação deste trabalho foram correlacionadas informações teóricas, por meio da revisão da literatura, com os resultados práticos obtidos após o estudo detalhado da lubrificação dos equipamentos da CSN e Gerdau Açominas.

O método utilizado nos dois casos foi o da comparação do desempenho do equipamento com a lubrificação anterior e depois com a lubrificação dimensionada para cada equipamento.

A comparação foi estabelecida por meio de inspeções visuais de inspetores experientes das próprias siderúrgicas onde os testes foram realizados e por meio do acompanhamento do desgaste dos equipamentos. No caso da Gerdau Açominas, além de inspeção visual foi usado a análise ferrográfica para medir performance da lubrificação.

No estudo de caso na CSN, também foi avaliada a questão financeira do projeto de otimização da lubrificação. Analisando o quanto gerou de economia para a empresa.

\subsection{Lubrificação do mancal do Convertedor na Gerdau Açominas - análise de performance por meio da ferrografia.}

Para adequar a lubrificação deste equipamento, a Gerdau iniciou, em conjunto com a Interlub Especialidades Lubrificantes Ltda, um estudo detalhado da lubrificação deste componente, a fim de determinar um lubrificante capaz de suportar às condições de trabalho deste equipamento.

O controle de desempenho da graxa foi feito por inspeções visuais e por meio de análise ferrográfica.

Sobre os critérios de avaliação foram consideradas as seguintes variáveis:

- Aspecto da graxa em operação. A mesma não pode apresentar separação de óleo;

- Contagem das partículas metálicas (provenientes do desgaste) por meio de ferrografia. Uma nova graxa deve diminuir consideravelmente a quantidade total de partículas metálicas resultantes do desgaste em relação à graxa anterior. 


\subsection{Lubrificação do plano inclinado do mandril na CSN}

Após avaliações sobre o desgaste prematuro das telhas do mandril da bobinadeira, chegou-se à conclusão de que a falha era consequência da lubrificação inadequada. Em parceria com a Interlub Especialidades Lubrificantes Ltda, iniciou-se a pesquisa para a formulação de uma graxa que suportasse às cargas de contato, à água e à alta temperatura que ocorre durante o enrolamento da bobina.

O controle do desgaste é feito por meio da medição da folga da telha e correlacionada com a tonelagem de aço produzida até que a folga atinja no máximo a 5,0 milímetros. Esse é o indicador do momento da troca de conjunto. Ao chegar nesse valor, inicia-se a programação de parada da bobinadeira para que o mandril seja substituído e enviado ao reparo.

Sendo assim, o objetivo é alcançar o máximo de toneladas produzidas até que o desgaste aumente a folga do conjunto para o máximo permitido de $5,0 \mathrm{~mm}$.

\section{RESULTADOS E DISCUSSÃO}

\subsection{Lubrificação do mancal do Convertedor na Gerdau Açominas - análise de performance por meio da ferrografia}

A graxa atingiu às expectativas, segundo as variáveis de controle estabelecidas. Como mostra a figura 7 , não houve separação do óleo base e nem tampouco vazamento. Logo abaixo na figura 6, observa-se a separação do óleo base.

Fica bastante evidente a diferença entre o resultado da lubrificação anterior e o da lubrificação proposta.
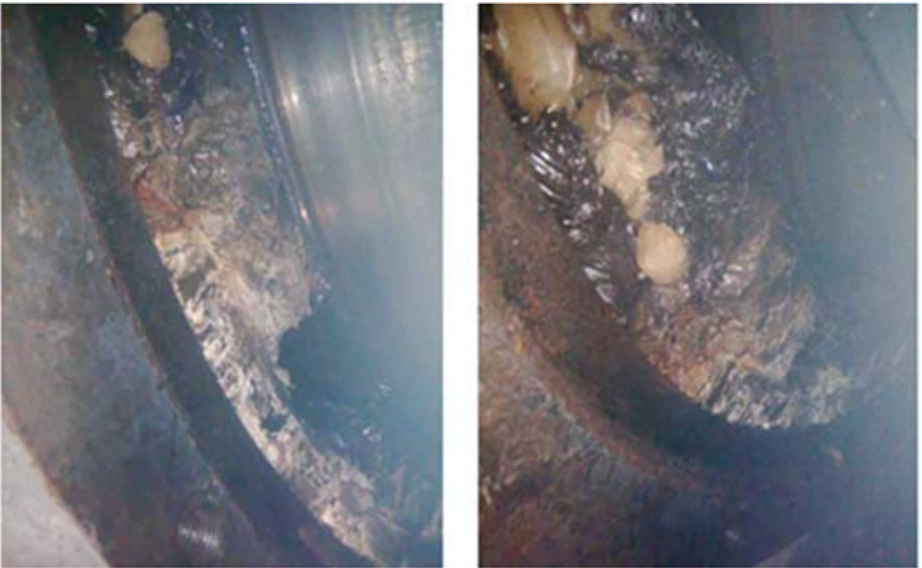

Figura 6: Lubrificação anterior apresentando separação de óleo.
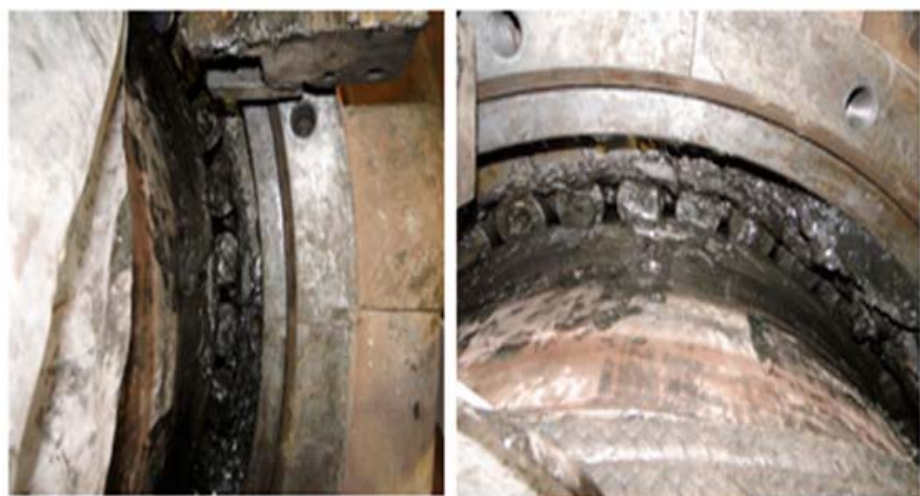

Figura 7: Lubrificação proposta para o convertedor. 
Com relação à contagem das partículas nas amostras de lubrificantes retiradas do mancal, houve decréscimo bastante acentuado ao longo de 3 anos com a lubrificação adequada, indicando que ela cumpriu seu papel.

Segundo Graças [11], as condições de lubrificação evoluíram de forma sistemática aonde o desgaste do equipamento foi reduzido drasticamente em função do estudo tribológico.

Com base na figura 8, é possível acompanhar a redução do desgaste do rolamento por meio da contagem das partículas metálicas encontradas na análise ferrográfica.

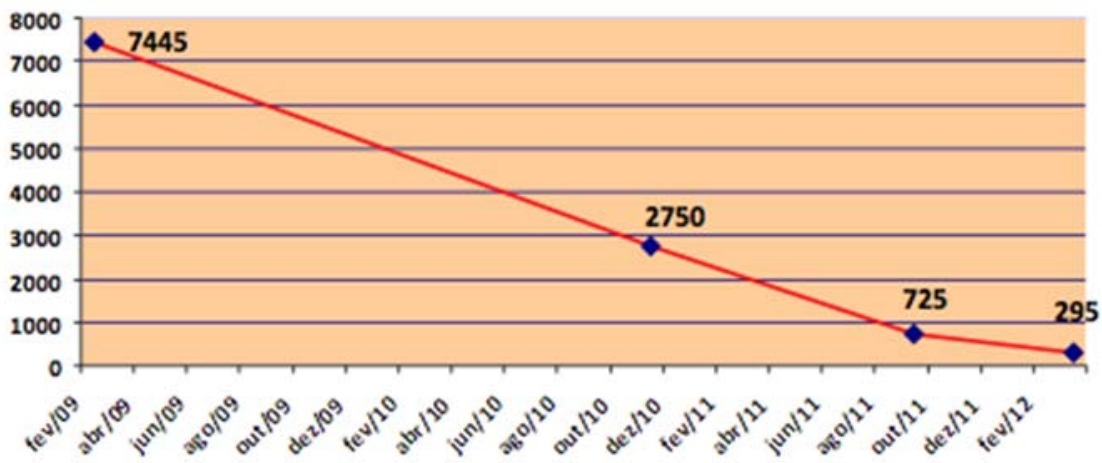

Figura 8: Gráfico de tendência L + S (mancal livre do convertedor).

\subsection{Lubrificação do plano inclinado do mandril na CSN}

O resultado do estudo da lubrificação adequada excedeu às expectativas. Foi possível perceber ganhos quantitativos significativos em três indicadores: mão de obra, sobressalentes e disponibilidade [14].

Com a lubrificação adequada foi possível reduzir em $50 \%$ os custos de mão de obra e sobressalentes (figura 9).
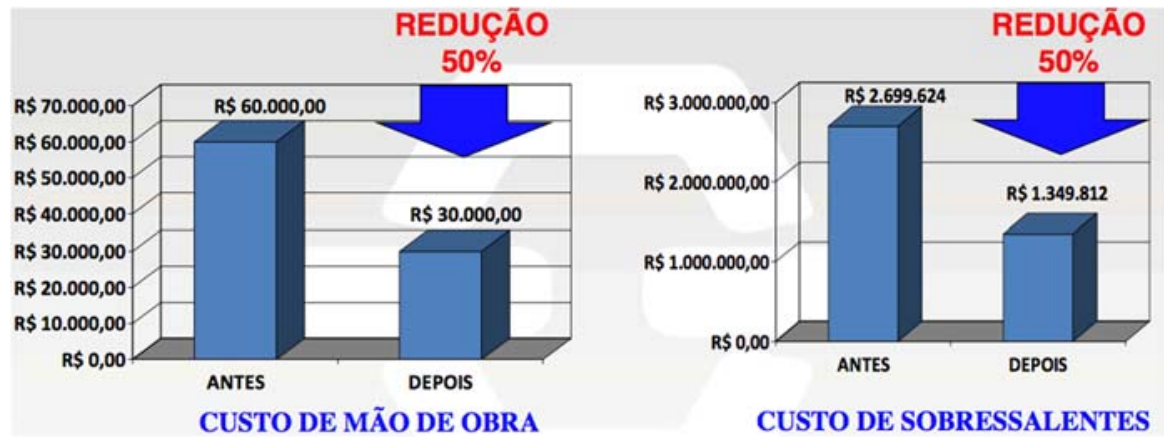

Figura 9: Ganhos com mão de obra e sobressalentes.

Redução de $50 \%$ no tempo de parada do equipamento (figura 10 ).

A tonelada de aço bobinado dobrou antes que a folga chegasse em $5,0 \mathrm{~mm}$, aumentando assim a produtividade (figura 11). 


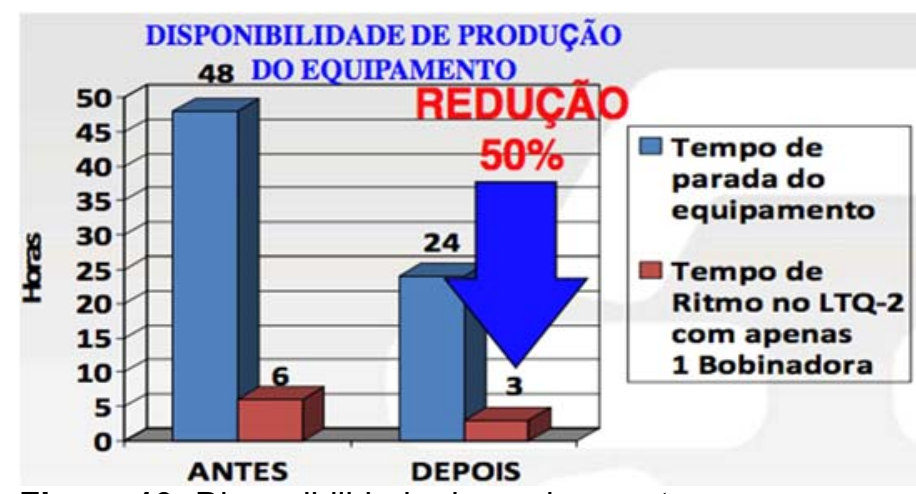

Figura 10: Disponibilidade do equipamento.

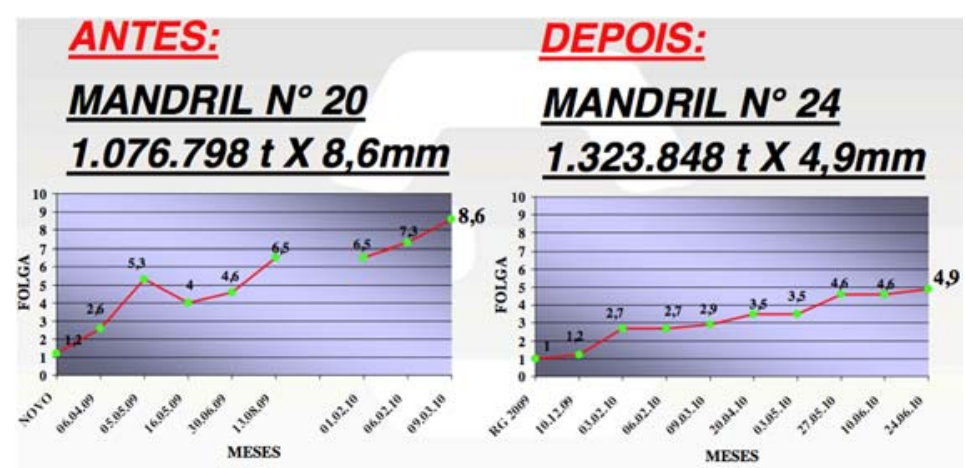

Figura 11: Controle da tonelagem VS folga.

A lubrificação adequada também facilitou o trabalho da manutenção do equipamento na oficina ou em terceiros, reduzindo o tempo de reparo. A figura 12 mostra a situação antes e depois da mudança na lubrificação.

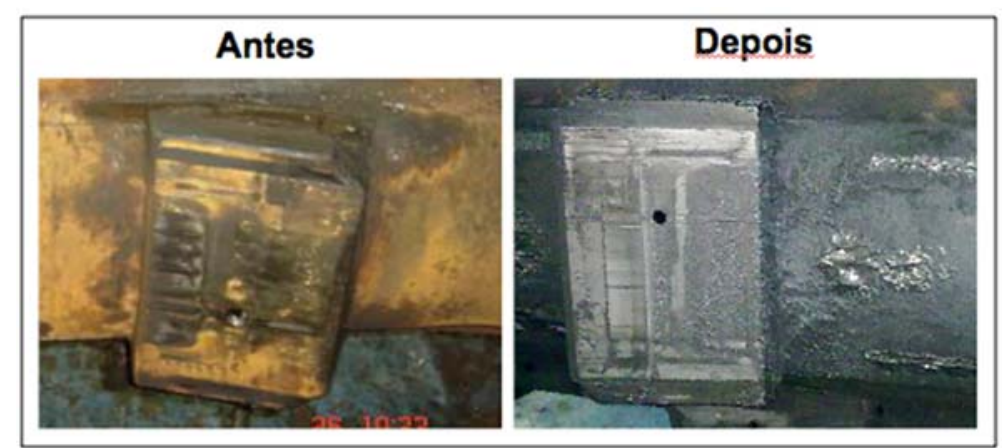

Figura 12: Comparação do antes e depois de parte do mandril.

\section{CONCLUSÃO}

Este trabalho comprovou que a lubrificação tem papel fundamental na operação das máquinas e na garantia da produtividade. Essa importância é demonstrada no mapa das principais falhas dos rolamentos, divulgado pelos próprios fabricantes, onde estão relacionados os pesos de cada causa da falha prematura.

Entretanto, este mapa também mostra, de forma disfarçada, mais causas de falhas indiretamente relacionadas ao lubrificante. Há $25 \%$ das falhas atribuídas à contaminação, sendo $20 \%$ por sólidos (poeira ou outros resíduos sólidos de partículas pequenas) e $5 \%$ pela contaminação de líquidos (água, emulsões, outros lubrificantes, entre outros). 
Essas falhas também podem ser associadas ao lubrificante porque há graxas com espessantes especiais que são capazes de funcionar como um selo mecânico, além de lubrificar o rolamento, impedindo que haja contaminação em todas as suas formas.

Com isso, a porcentagem de falhas prematuras do rolamento oriundas do lubrificante (no caso de um rolamento lubrificado com graxa) sobe para $80 \%$.

Foi observado outro ponto de extrema relevância: o termo lubrificação está diretamente relacionado pela maioria dos autores pesquisados durante à revisão da literatura como sendo - o resultado da aplicação de uma substância capaz de reduzir atrito e desgaste. Ou seja, o foco principal está voltado apenas para o lubrificante como sendo o responsável por este feito. No entanto, o termo "lubrificação" é muito mais amplo e exige a observância de outros fatores correlacionados.

É evidente que o lubrificante é importante, mas também deve ser levado em consideração outros fatores como: a máquina, o método de aplicação e o homem 1 .

A lubrificação deve ser interpretada como sendo a intersecção das variáveis: lubrificante, máquina, método de aplicação e o homem.

Esta hipótese se comprova observando os excelentes resultados obtidos nos dois estudos de caso vistos neste trabalho, no qual a lubrificação dimensionada sob medida para cada máquina trouxe significativo aumento de produção e/ou redução de custos.

Além de ganhos quantitativos controlados por indicadores tangíveis de produtividade ou custos, a lubrificação adequada, projetada sob medida para cada equipamento, traz inúmeros outros ganhos intangíveis e muito relevantes como: mais segurança no trabalho da operação e manutenção, menos resíduos de lubrificante descartados no meio ambiente, maior disponibilidade do equipamento devido à redução de paradas programadas ou não programadas e disponibilidade de recursos humanos e financeiros para outros projetos.

\section{Agradecimentos}

À ABM por promover este importante encontro que permite a troca de conhecimento para o setor.

À CSN pela parceria de longos anos e que culminou na preparação deste trabalho.

À Gerdau pela parceria e informações fornecidas para contribuir com este estudo.

À Mariana M. De Moraes pela colaboração na edição deste trabalho.

\section{REFERÊNCIAS}

1 Worldsteel Association. Steel annualy 1980-2014. 2015. Acesso em: 30/03/16.

Disponível em: https://www.worldsteel.org/statistics/statistics-archive/yearbook-

archive.html.

2 Confederação Nacional das Indústrias. Produtividade brasileira é a que menos cresce entre 11 países. 2015. Acesso em 02/04/16. Disponível em:

http://www.portaldaindustria.com.br/cni/imprensa/2015/02/1,56840/produtividadebrasileira-e-a-que-menos-cresce-em-relacao-a-11-paises.html.

3 McKinsey Global Institute. How Brazil can grow. 2006. Acesso em: 31/03/16. Disponível em: http://www.mckinsey.com/global-themes/americas/how-brazil-can-grow, p. 8-13

\footnotetext{
${ }^{1}$ Homem é tratado neste trabalho como o profissional responsável por executar a aplicação da graxa. O lubrificador.
} 
4 Confederação Nacional das Indústrias. Indicador de Custos Industriais (ICl). 2015. Acesso em 02/04/16. Disponível em: http://www.portaldaindustria.com.br/cni/publicacoes-eestatisticas/estatisticas/2015/12/1,42619/indicador-de-custos-industriais.html.

5 Robertson, WLI. Lubrication in practice. Second edition. New York: Ed. Macmillan Press LTD; 1984, p. 3-6.

6 Gomes. MC, Lima. CRC, Silva. IB. Aplicação da lubrificação autônoma como ferramenta essencial do TPM: Uma abordagem prática. XXXII Encontro Nacional da Engenharia de Produção. 2012, p. 3-5.

7 Cash. W. What is lubrication? Machinery Lubrication. 2012. Acesso em: 03/04/16. Disponívem em: http://www.machinerylubrication.com/Read/28766/what-is-lubrication.

8 Carreteiro, RP, Moura, CRS. Lubrificantes e Lubrificação. São Paulo: Ed. Makron Books do Brasil Editora Ltda; 1998, p. 99-100.

9 Gunther, RC. Lubrication. First edition. Philadelfia: Ed. Chilton Book Company; 1971, p. 210-212.

10 Schaeffler. Rolling bearing damage. Recognition of damage and bearing inspection. 2001; WL82 102/3EA, p. 4-13.

11 Pereira. JG. Utilização da técnica de análise ferrográfica para aumento da vida útil de rolamentos dos conversores: Caso de sucesso. Projeto de iniciação científica UFSJ. 2012, p. 5-8.

12 Klamann, D. Lubricants and Related Products: Synthesis, properties, applications and international standards. Esso AG Research Center. Florida: Ed. Verlag Chemie; 1984, p. 389-391.

13 FAG Sales Europe Iberia. Lubricación de rodamientos. 1997; WL 81 115/4SB, p. 24-33.

14 CSN, Apresentação Mandril do LTQ\#2, 2011. 